\title{
The Aesthetic Features in Diwan of (Kalpna Singh-Chitnis) Bare Soul
}

\author{
Khader Mohammad Abu Jahjouh* \\ Assistant Professor, Arabic Department, Islamic university-Gaza
}

*Corresponding Author: Khader Mohammad Abu Jahjouh, Assistant Professor, Arabic Department, Islamic university- Gaza.

Abstract: The present study aims to explore the aesthetic of diwan Bare soul by poetess( Kalpna SinghChitnis $)\left({ }^{1}\right)$ as he attempts to analyze rhetorical forms such as; simile, metaphor, repetition, and the pun (words play) depending on the descriptive analytical approach.

Keywords: Poetry. Bare soul, kalpna singh, rhetorical, aesthetic, simile, metaphore.

\section{INTRODUCTION}

After researcher had read the poetry of the poet (Kalpna Singh-Chitnis) in her beautiful diwan (Bare Soul). I sensed that there is a wide area for its aesthetic, need to study its aesthetic features and know its stylistic advantages.

So searcher wanted to write about the composition of the poetic image, which composed the poems of Diwan, through questioning the texts away from within the components of thought with the possibility of analyzing what the aesthetic form reflects of the meanings.

\section{Previous Studies}

Researcher didn't find specialized academic studies about the current diwan sample study, but I found some impressions of the writers, and critics of the poet's friends, accompanied by the poet, at the end of the pages of the Diwan poetry, which consists of nineteen poems are respectively: : Jungle ,River of Songs ,Ancient Quest, Ancient Love , Ancient Remorse ,In the Vessel of Knowingness ,Rustling Winds ,Rain, Firebird, Touched By The Devil, Devil's Dilemma, Unkind, Being Nothing and Everything, A Pale Monday Morning, Conversations with a Friend, Coming Home, On A Good Grey Day, ,Fourth Moment, and Bare Soul.

In the introduction to the book written by Jennifer Reeser, she called kalpna is as the Jewel of the East (Chitnis,2015,xvi) and she pointed to her poetic status, the awards she got, and associated with some English poets such as: Percy Bysshe Shelley:" "In one poem, for example, she might be speaking with English poet Percy Bysshe Shelley, through her use of the nightingale" (Chitnis,2016,Xiv).

( $\left.{ }^{1}\right)$ "Kalpna Singh-Chitnis is an Indo-American poet, writer, filmmaker and actor based in California, USA. Author of "Bare Soul" and three collections of poems in Hindi, she won the prestigious "Bihar Rajbhasha Award" (1986-87) given by the government of Bihar, India, for her first poetry collection "Chand Ka Paivand" (Patch of Moon) before she was 21, and was given the title of "Bihar Shri"'(Jewel of Bihar) in 1988. She also received the "Rajiv Gandhi Global Excellence Award" in 2014 for her contributions to literature and cinema, and was nominated for"Honor Of Yeast Litteraire" by "Levure Litterarie" magazine. Kalpna's literary works have been widely published in the Indian subcontinent, Europe and North America. She is also the creator and editor of "Life and Legends" literary journal, and serves on the Editorial Board of "Levure litteraire" in Paris, France. Kalpna received masters degree in Political Science from Magadh University, Bodhgaya, and studied film directing at the New York Film Academy, Universal Studios, in Hollywood". For more details, look, Bare Soul, Copyright @ 2015 . Partridge India p101.102 
Those impressions are only illuminations and signs, not deepened in the study of aesthetic phenomena, except for some references here and there, Except for the comment written by (Satyapal Anand), where he tried to comment on some of the poems, and a statement of the features like dramatic monologue which embodies the Yang-yin conflict, and use the Hindu mythological story in the poetic style, He also pointed out that the poems were made up of passages, but he did not delve deeper into the study of image and method components, Just point to Intellectual Subjects.' (Chitnis, 2016, 91)He also did not delve deeply into stylistic phenomena, and the aesthetics of the image, which were filled with poems. Therefore the study will be responsible for the critical and analytical approach of the images, and the beauty of the rhetorical especially simile and metaphor and the composition of the poems in passages, as well as the dramatic structure including monologue and dialogue.

\section{STUDY APPROACH}

The current study used the analytical descriptive approach which emanates from within the text and its relations within the context is the best way to approach the aesthetics of the poetic image.

\section{COMPONENTS OF POETIC IMAGE}

Diwan bare soul by Kalpna Singh Chitnis journey in the emancipation of the contradictions of life, it's search for love, beauty, and goodness, and diving in the depths of the self because "Imagery in poetry is an appeal to the senses through words. Through the senses the emotions and intellect of reader can be swiftly stirred" (Burton, 1977, 97).

There are many poetic and expressive features such as: metaphor, simile repetition, and pun.

\section{First: Metaphor}

Metaphor is "a figure of speech in which a word or phrase literally denoting one kind of object or idea is used in place of another to suggest a likeness or analogy between them (as in drowning in money); broadly : figurative language - compare simile" (Webster, ,).

Abdul Qahir al-Jorjani says about metaphor; "You see mineral a lively speaker, And the Not eloquent eloquent, And Dumbness objects Fluent, and hidden meanings clearly manifest (al-Jurjani,1991,43).

The metaphor gives the poet an opportunity to express his emotional stores by deviation and moving away from the familiar rolling meaning, To a new meaning pulls the receiver, surprising in terms of amazing creative.

"In composing and reading poetry, poets and readers use the same cognitive principles of embodied understanding. We both create and conceptualize our world through the container metaphor, and we do so through the process of analogical mapping" (Freeman, 2000).

So the poet's success in the composition of his poems, as well as grabbing the amazing moments, which raise the mind of the recipient, and his conscience. And the familiar use of maps of intellectual awareness, to create new and exciting things.

"This projection is all the more familiar to us because it is an instance of the conduit metaphor: a message is an object in a container; communication is transferring an object spatially from the speaker to the hearer (Turner and Fauconnier, 1995,).

The poet used many structures of metaphor in her Synthetic poetry. like her saying in (Jungle):

'The jungle greets century a new year,

centuries greet millenniums;

millenniums greet eternity,

and eternity greets the sacredness in us (Chitnis,2016,1).

In this passage the poet has been given human qualities for nature and time, so the jungle has become greets to the centuries, and the centuries greet the millions, and the millions greet eternity, which in turn pays tribute to the sacred feelings and meanings within humanity.

It's successive and dynamic images that open space of the text of meditation in the movement of time and its creation, and gives the recipient a space to reflect meditation and surprise. 
All these $t$ images depend on the diagnosis of the components of nature, which in turn gives the text new relationships and deep signals commensurate with the dialectic of the process of time and life.

The poet says in a poem (Ancient Quest);

'It's now time for me to empty my soul,

roll into the abundance of silences,

to hear my voice...

It's now time for me to pour myself

into the chalices of some restless hearts,

and let my intoxication be the exhilaration of others...

It's now time for me to become one, with the vastness of the ocean,

and let all the waves come crashing,

to shatter my pride...

It's now time for me to light the candles, and let myself be a firefly,

entering the periphery of your light,

and become immortal...

It's now time for me to wear the charms you gave me once,

feel the warmth of your invisible embrace,

and let my heart thaw..'(Chitnis, 2016, 10).

The poet in these lines embodies the soul, in the form of a material vessel which needs to be emptied of its weight, and unloading here tends towards the abstract moral dimension, It opens the text space on the meaning: the statement and the revelation; to get rid of the rubble of concerns and sorrows as hinted at the significance(to empty my soul) Confirms the space of the previous text and its potential, saying (to pour my self into the chalices of some restless hearts, ) It metaphor metaphorizes the soul of this abstract mental form the state of anxiety appears of context, of the metaphors she used this sentence (to shatter my pride) Which epitomizes the concept of pain, anxiety and puzzlement, and embodies pride in a material form that can be shattered dreams.

So that, there are many metaphors, distributed on the poems of the Diwan such as; " let's dazzle, when the sun plays hide and seek;'(Chitnis,2016,2)."It's now time for me to hear, the heart of the ocean, throbbing in a seashell, washed off the shore, a heart very similar to yours...!' (Chitnis,2016,11).In a long time silences have found their meanings not spoken in words, but only to be written with our hands on the forehead of time'(Chitnis,2016,21). and other metaphors.

\section{Second; Simile}

A simile is a figure of speech that compares two different things in an interesting way. The object of a simile is to spark an interesting connection in a reader's or listener's mind. A simile is one of the most common forms of figurative language. (examples.yourdictionary.com)

The poet used the rhetorical analogy (simile) in many of her poems in order to enhance the poetic image and give her an aesthetic touch that suits her poetic condition. And stored emotions, as she says in poem (Jungle):

Let's rise in gratitude,

and blossom like wild flowers;

open to the core,

and perfume the jungle!'(Chitnis,2016,1). 
Tenor (Comparative) is (we blossom), and Vehicle (like it) is (wild flowers). That simile gives space of text large area of sings, Because flowers store the meaning of beauty, and adjective wild increase it meaning of innocence, goodness, spontaneity, and openness stored in life of flowers. Significance of life and happiness, amid the jungle of pain.

The case goes beyond the sheer resemblance to wild flowers; to a latent meaning within the same poet, this meaning is highlighted by the signifiers used in simile; it is a call for optimism, joy, and happiness, to get rid of the burdens of Jungle life, Although the flowers of the forest suffer and are trampled and tormented, it given beauty and life.

Another example of the simile, the poet says in a poem (River of songs):

Truth is not always what is said;

truth is not always what is heard;

sometimes, the truth exists somewhere in the middle,

and flows with the course of life like a Silent River;

committed to the world on both its sides,

searching for its way to the ocean(Chitnis,2016,9).

Imagery of the truth by flows a silent river, involves the meanings of the relentless quest, to reach the mystery of existence, the spring of life, and carries in itself the concept of transformation and continuous renewal, because the water of the river is renewed at every moment, and we don't cross the river twice, as Heraclitus says.

The truth is a secret that begins by seeking and ending with it, like water flowing from the ocean and returning to it through the rivers, and The silence of the river suggests the tranquility that carries with it a great life, which the poet wants to point out,

Another example of the simile, the poet says in a poem(ancient love)

All night,

you held my hand by my bedside,

and I slept like a baby

all night(Chitnis,2016,23).

In this passage the poet plays on the child's innocence chord, in order to show her human need, to philosophical love, which calms her and removes her fear.

She sleeps in his arms like a child who needs a little tenderness, He hugs her with his arms tenderly in the dark hours of the frighten night. The night here is a symbol of the horror of life and the unknown. Perhaps this explains the fact of ancient love which she means.

'The fragile ground we stand on is stone cold

and in the darkness, as we unchain each other

from our hurt and remorse,

the lava of centuries oozes from our hearts,

and we float into each other's eyes.

We savor the darkness bestowed upon us,

leading us toward each other,

our wings are bruised,

and there is no sky above our heads,

but we have what the heavens don't;

like a twine in the candle,

we burn together, we light together! (Chitnis,2016,24).

International Journal on Studies in English Language and Literature (IJSELL) 
Signifiers (stone cold, darkness, remorse, lava, oozes, float, bruised, wings, burn) opened the space of text on a state of consciousness associated with it which causes pain and chills because that ; (darkness) is awe, (Bruising) is pain, (floating) is alienation. awesomeness, and lost self, confirmed by the broken wings and meeting of the cold and the fire of the Lava increases the sad scene which overlooking on torment .

So the poet used the combination structures such as: (we - each other - our hurt - our hearts - toward each other- our wings - our heads - we burn together - and light together) which suggests its human need for familiarity and serenity, and it opens the space of text to the meaning of union and harmony with the other. Moreover composition of " like a twine in the candle," raises the meanings of the effort to love the kindness in others. It recites the concept of spiritual union which radiates light, growth and renewed life.

and she used more similes in (Ancient remorse) for example, the first section where she says:

My thoughts are void of words;

like a tide on a full moon crashing by the shore,

I return to myself...!

My mind is void of thoughts;

like a night without light, reaching unreachable,

I surprise myself...!

The winds are void of life;

like an unmarked grave,

with my destiny to wait,

I identify myself...!

My thirst is void of mortality;

like a wanderer in the desert, searching for the rain,

I mystify myself...!

The sky is void of horizons;

like a nightingale in the darkness,

singing to the moon,

I renounce myself....! (Chitnis, 2016,27).

The previous section of the poem evokes the feelings of pain, which is resulted of the signifier, and the signified resulting, that reflect the poetic state of the poet, and provides the recipient with a scene of her puzzlement and torment, and her search for truth and psychological comfort..

So the imagery of the analogy(simile) came sequentially, In this way, the receiver attempts to connect between the elements and becomes confused, as well as the empty thoughts that resemble the dark night without moon .

These images consistent with confusion and fear. whereas the night without a moon carries the meaning of fear she has reached a state of astonishment, and the inability to heal the meanings of things, because of a state of anxiety, and unknown mysterious fear, that leaves the mind without concentration.

In poem (RAIN) she used mor simile Sequentially

Sad like a monsoon sky,

weepy like pouring rain;

aimless like rolling clouds, 
silent like vast plains.

Rain, come down,

extinguish me,

I'm inflamed!

Shiver me like a twig breaking from a tree,

shatter me like a drop fallen from the roof,

bring me down,

I'm nothing but a mud house! (Chitnis,2016,42).

In this passage, the poet is sad, and the state of sadness dominated her feelings, so she presented the state of sadness through simulated image, her sadness is like the sadness of the seasonal sky.

Including the heavy rain, and in this reference to the meaning of the metonymy, which point to the intensity of tears, so the next simile came to confirm this meaning and repeats in another form more frank they are tearful like heavy rain and like clouds that swaying in the sky, It is one of the most beautiful similarities, in addition to the state of sadness, the state of psychological crash is like a broken branch and a drop of dew falling from the ceiling, and fade like crushed atoms.

She has reached a state of ignition and depression, rain only extinguished, as if she want to resurrect, rain brings life, symbol of life, new power, energy and purity and beauty, is one of the four elements of nature, its roots, dust, fire, air, and water. All these met in the preceding paragraph through analogy and successive images.

\section{Third: Repetition}

Repetition is a device of rhetoric, It's being used to convey ideas, feelings, and speech. It is : repetition a word or a phrase in a longitudinal or horizontal manner. The poet used repetition as a rhetorical form, sometimes spontaneously in order to be consistent with the poetic case.

"Repetition is a literary device that repeats the same words or phrases a few times to make an idea clearer. There are several types of repetition commonly used in both prose and poetry. As a rhetorical device, it could be a word, a phrase or a full sentence, or a poetical line repeated to emphasize its significance in the entire text. Repetition is not distinguished solely as a figure of speech, but more as a rhetorical device."(https://literarydevices.net/repetition)

In fact, repetition is almost devoid of speech, so it should be used rhetorically to make an impact, and the composition of the poetic beauty, so "All verbal production implies a repetition. The constitution of lexical fields is done by repetition of seems, but repetition is identified as a construction figure only if the lexical material is concerned"(Formilhague, 2010, 26).

The curent study has identified some of the features of repetition such as repetition of specific words which were repeated in the context of poems, sentences and methods, For example she says:

"Let's bare ourselves, and bask in the beauty of the jungle.

Let's throw away our covers, we've had enough of them!

In the jungle there is no need to pretend, let's just be, whoever we are.

Let's be the lions, eagles, wolves, hyenas, deer, doves, deities or serpents; if that's what we are...

Or let's be the trees, hills, rocks, dunes or fallen leaves on a winding trail.

Let's celebrate our thirst searching for a stream;

let's glow in our skin in the darkness and light;

let's dazzle, when the sun plays hide and seek"

let's bare our souls, and keep the sacredness of the jungle;

let's discover now, our wild inner beauty! (Chitnis,2016,2, 3). 
The formula (let's), repeated ten times, with verbs changing the demand beyond. (Let's bare. Let's throw away, let's just be, whoever we are, Let's be the lions, let's be the trees , Let's celebrate, let's glow; let's dazzle, let's bare our souls, let's discover) that opens the space of the text, On the meaning of the removal of restrictions, surrender, and injustice, and the request for freedom from restrictions, and also promotes the concept of spontaneous life.

As well the verb (bare) repeated, which emphasizes the idea of freedom and honesty as she said " In the jungle there is no need to pretend".

This formula has been repeated in a poetic style in poems of diwan, thirty-nine times, and this confirms the psychological fact. which live in the subconscious of the poet and Inners energy of rebellion and revolution and freedom from the constraints of reality as if she suggest to the recipient the cruelty of life.

In Jungle where the strong eats the weak, there is no place for the weak, nor a safe life for them. The jungle is symbol to the large world so in the jungle everyone should adapt himself to reality and live in the safety that is available to them as much as possible.

Another example, She says in poem (river of songs)

"Who claims to know what the river is all about?

Those who came in their boats of pride,

could barely make it to the shore.

Those who came without any prejudice,

could never surface to tell its depth.

Who claims to know the river?

Not the river itself.." (Chitnis,2016, 8).

Formula which is ("Who claims to know what the river) Is an question sentence has been repeated, it's open the space of text to large of Interpretation, because the river is a symbol of life, which is carrying more much of humanity worries, troubles, and fluctuations.

The nature of the river / symbol is a mysterious fact, because it has many secrets. For this reason, truth / fact river and life, unknown, even on the river itself.

The poet used repetition in many poems. why not?. The repetition of sounds and words produces new connotations and gives the rhythm a distinct tone. "When sounds repeat, the greater is the tendency to bring the words into relation, a psychological phenomenon literary critics have noticed in rhyme equivalence. Thus, when phonetically similar but not identical words appear in a formal pattern or near each other, tension is set up between sameness and difference, resulting in the impression that shifting has occurred". (Freeman, 18

\section{Fourthly: Pun (Words Play)}

The pun allows to the poet to present his feelings to the recipient/ reader in a way that prompts the recipient to meditate and try to be consistent with the poetic state of the poet.

"Puns and words play occupy a significant position in literature as well as in various ways of reflecting on and conceptualizing literature" (Kjerkegaard, 2011, 1).

Successful beautiful poem that has the potential of esthetic and radiation, It should have a degree of linguistic energies, vocal abilities, and expressive, this may be through the use of the idea of verbal manipulation. "Paronomasia is one of the essential elements of verbal creation, but a pun introduced into a conversation turns its back on the sense of the conversation and sets up a self-contained verbal sound-sense pattern in its place." (Fry,,,276).

Any poet who wants his poems to be vital and influential, prefer to improve the use of his vocabulary, and select it carefully and accurately. So That his poems gains its life "This language is characterized by living words, vocal overtones, radioactive, linguistic and compositions, with correlations attitudinal, reflecting tunes emotions abundant, which stems from the human experience" (Qasim, 2006, 32). 
The poet has not used much puns, the search monitor has some of simple word's play features, such as:

When I try to reach you, you step back;

when I try to let go, you follow me everywhere...

I don't know,

whether you are my obsession, or I'm yours? (Chitnis, 2016,16)

The pun in these lines is based on the idea of a double exchange, in the reflection of a contradictory idea, as she tries to approach him, but he distanced himself from her, and when she let him to go faraway, and leaves her he follows her.

In the following line also (whether you are my obsession, or I'm yours?) adopted pun through the exchange of the contextual meaning, between being her obsession, or she is his obsession.

Words play (pun) attracts the receiver and push him to attention and explore what the idea of syntax poetic language. and meanings which are given through it.

Another example she says;

You gave me nothing;

I had nothing to take care of,

nothing to worry about;

you set me free from everything.

You took everything away from me,

and became my prisoner for the lifetime. (Chitnis, 2016, 37).

There's dialectic of reciprocal relationship between the giving and the taking because each taking may be giving, whether by satisfaction or by force.

She used simple past tense (gave) with tow objects the first is (me) and the second is (nothing), she didn't use the formula (you didn't give me (anything) because the first formula -where the action is positive, imagine to the recipient at first glance 9 that he gave her, and then surprised by the existence of the formula denies the occurrence of the act is nothing, and thus achieve the manipulation of mental perception through the pun and word play.

These simple reflections provide an opportunity, for reflection and conclusion, and this is a necessary requirement to enhance the value of the poetic sensation, between the poet and the reader.

Another example, she says:

Rain,

I must give all,

what it takes me to be me,

what it takes us to be us,

without having each other...!

Rain, continue to fall,

I have survived all,

I will survive all! (Chitnis, 2016, 43-44).

In this poetic context the pictorial relied on the being of the transformation from (ego) in its effect, or form's (me) To (us), This shift is reminiscent of the poet's aspiration towards social stability, where each one needs the other, without dominating, This trend is confirmed by her saying: (without having each other !).

This transformation from singular to plural expresses the tendency of the poet to be stripped of the supremacy of the ego and super- ego. and her passion for social integration.

As if the rain washed everyone, from the desire to control others, and gives them harmony in their life.

There's another words play between past perfect tense(I have survived all) and future present simple (I will survive all) This shift from the past perfect to the future, points to the optimism of the poet, 
who hope and they wish that there is time for every one gone to live in fertile ground and glad, happy and safety life.

\section{CONCLUSION}

After this approach literary criticism, and diving in the texts of Diwan Bare Soul, to know its components and forms and aesthetic features, It is clear that he found the employment of a number of rhetorical capabilities in a way that serves the poetic situations, that penetrated the context of the poems.

From these aesthetic features, metaphors emerged as an expressive energy of deviation on the familiar and expected, , arousing the recipient and pushing him to further contemplation. as the simile came in order to enhance the poetic image and give her an aesthetic touch that suits her poetic condition. The poet also reported the value of repetition in deepening the idea and submitting in deep and stress meaning significance as well as pun (words play) were used in order to stir the feeling and deepen the idea and to impress the recipient.

\section{REFERENCES}

[1] Chitns, Kalpna Singh, (2015) Bare Soul. Partridge India.

[2] Burton,S.H.( 1977) The criticism of poetry, longman, 3rd impression.

[3] https://www.merriam-webster.com/dictionary/metaphor

[4] al-Jurjani, Abd al-Qahir(1991). (Asrar al Balaghah) Secrets of rhetoric.

[5] Freeman, Margaret H,( 2000) Poetry and the Scope of Metaphor: Toward a Cognitive Theory of Literature . Metaphor and Metonymy at the Crossroads: A Cognitive Perspective, Antonia Barcelona, ed., pp. 253-281, Mouton de Gruyter, (2000). Berlin and New York. Available at SSRN: https://ssrn.com/ abstract $=1427868$. P.2

[6] Turner, Mark and Fauconnier, Gilles (1995) “Conceptual integration and formal expression”.: Metaphor and Symbolic Activity, 10(3).

[7] http://examples.yourdictionary.com/examples-of-similes.html

[8] https://literarydevices.net/repetition/

[9] Formilhague, CatherineL,( 2010) Les Figures de style. (C) Armand Colin, pour cette nouvelle édition toute. Parise.

[10] Kjerkegaard , S. (2011). Seven Days Without a Pun Makes One Weak. Two Functions of Wordplay in Literature and Literary Theory, Journal of language linguistic .3(1).

[11] Fry, Northrop, (1990) Anatomy of Criticism four essays, Princeton Univercity. , New Jersey. U.K. Tenth printing.

[12] Qasim, Adnan Hussein,(2006) the Arab language of poetry, Arab House for Publishing and Distribution, Cairo, Second Edition..

\section{AUTHOR'S BIOGRAPHY}

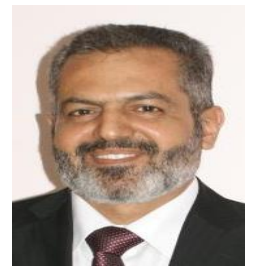

Khader M. Abu Jahjouh, was awarded the Ph.D. degree in Arabic (literature, and criticism) from the Department al Jinan University-Tripoli Lebanon in 2012 .He works as an assistant professor in the department of Arabic in Islamic universityGaza, Member of the Palestinian Writers Union, Member of the Association of Writers and Authors, He issued six collections of poetry, participated in many poetry revelry and literary gatherings, and television, radio and press interviews were conducted with him, and He has published many articles and researches.

Citation: Khader Mohammad Abu Jahjouh."The Aesthetic Features in Diwan of (Kalpna Singh-Chitnis) Bare Soul. International Journal on Studies in English Language and Literature (IJSELL), vol 5, no. 10, 2017, pp. 19-27. doi: http://dx.doi.org/10.20431/2347-3134.0510003.

Copyright: (c) 2017 Authors. This is an open-access article distributed under the terms of the Creative Commons Attribution License, which permits unrestricted use, distribution, and reproduction in any medium, provided the original author and source are credited. 